\title{
Proposta de sequência didática com o uso de tecnologias digitais para o desenvolvimento do letramento científico
}

\author{
Monalisa Lais Oliveira da Silva (MPNTDE/UniCarioca) \\ Melissa Tais Oliveira da Silva (MPNTDE/UniCarioca) \\ Arnaldo Barbosa de Melo Filho (MPNTDE/UniCarioca) \\ André Cotelli do Espírito Santo (NUCAP/UniCarioca) \\ Ana Paula Legey (NUCAP/UniCarioca)
}

\section{Resumo}

Este artigo objetiva elaborar uma proposta de Sequência Didática que fará uso de duas tecno-logias digitais, a qual será capaz de contribuir de forma positiva para a formação de alunos letrados cientificamente e que poderá ser adotada em espaços não formais de aprendizagem. $\mathrm{O}$ artigo apresenta uma fundamentação teórica que disserta sobre o Letramento Científico nos anos iniciais do ensino fundamental, articulando esse conceito com o de espaços não formais de aprendizagem e Educação Ambiental. Como metodologia, os autores deste artigo realiza-ram uma visita ao Sítio Roberto Burle Marx para refletir sobre a elaboração de uma Sequência Didática que proponha uma pesquisa de campo no local, com a utilização de dois recursos tecnológicos. Foi realizada também uma descrição e análise das duas tecnologias utilizadas e, por fim, uma reflexão sobre as oportunidades oferecidas por esta atividade para a promoção do letramento científico nas escolas. Concluiu-se, por meio dos resultados apontados, que a Sequência Didática elaborada poderia ser um dos caminhos percorridos pela escola para contribuir no desenvolvimento de alunos letrados cientificamente, por meio de reflexões de forma democrática e com uma postura crítica diante dos problemas de seu tempo e de seu espaço.

Palavras-chave: Letramento Científico; Sequência Didática; Tecnologias Digitais; Espaços Não formais; Educação Ambiental.

\begin{abstract}
This article aims to elaborate a proposal for a didactic sequence with the use of two digital tech-nologies capable of contributing positively to the formation of scientifically literate students to be adopted in non-formal learning spaces. The article presents a theoretical foundation that talks about the Scientific Literacy in the initial years of elementary education, articulating this concept with the Non-formal Learning Spaces and Environmental Education. As a methodology, the authors of this article made a visit to the Roberto Burle Marx Site to reflect on the elaboration of a Didactic Sequence that proposes a field research in the place, with the use of two technological resources. It was also carried out a description and analysis of the two technologies used and, finally, a reflection on the opportunities offered by this activity for the promotion of scientific literacy in schools. It was concluded, through the results pointed out, that the elaborated didactic sequence could be one of the ways the school went to contribute to the development of scientifically literate students, through reflections in a democratic way and with a critical posture to the problems of Your time and your space.
\end{abstract}

Keywords: Scientific Literacy; Didactic Sequence; Digital Technologies; Non-formal spaces; Environmental Education. 


\section{Introdução}

A presente pesquisa se propõe a apresentar uma proposta de prática pedagógica que contribua para o desenvolvimento do letramento científico nos anos iniciais do ensino fundamental. Discorre sobre a Educação Ambiental (EA) no contexto escolar, a partir de uma postura investigativa que favoreça a valorização do protagonismo infantil, do pensamento científico e que transcenda os muros da escola. Importante é sinalizar que não se incluiu como procedimento metodológico desta pesquisa uma aplicação da referida atividade educativa com alunos dos anos iniciais, mas sim uma reflexão sobre suas contribuições para a formação de alunos letrados cientificamente.

Sua elaboração se justifica no fato de que, de acordo com Costa (2016, p. 13), ainda temos uma educação formal pautada predominantemente em uma abordagem tradicional, com professores que desconsideram os recursos que existem fora dos livros didáticos, fora dos muros escolares, e que podem possibilitar o desenvolvimento de uma ciência real, que atenda às exigências da sociedade contemporânea.

Nesse sentido, desenvolver uma proposta de Sequência Didática (SD) interdisciplinar (envolve várias esferas do conhecimento como Língua Portuguesa, Matemática, Geografia e Ciências) com abordagem investigativa e pautada no uso de duas tecnologias digitais - o PlantNet (detalhado na subseção 6.1) e o Google Earth Pro (detalhado na subseção 6.2) - pode ser uma prática pedagógica eficaz para o desenvolvimento de alunos letrados cientificamente? Acreditamos que a referida SD poderia ser uma alternativa eficiente neste processo de desenvolvimento do letramento científico nos anos iniciais do ensino fundamental e objetivamos neste artigo, portanto, elaborar uma Sequência Didática baseada nesses princípios, que articule o uso das duas tecnologias digitais supracitadas e que seja capaz de contribuir de forma positiva para potencializar a ampliação de práticas sociais de leitura e escrita científica.

É importante deixar claro aos leitores que este artigo tem o propósito de apresentar uma futura proposta de uma Sequência Didática interdisciplinar a ser usada, e não uma pesquisa de campo e aplicação e análise com aprendizes. Existe sim uma sugestão de prática educativa diferenciada que possa vir a ser utilizada em ambientes em diferentes espaços de aprendizagem.

\section{Fundamentação teórica}

A necessidade da conservação e da defesa do meio ambiente é indiscutível em nossa sociedade hoje. Todavia, ainda é comum que a educação formal transmita aos educandos um olhar fatalista diante da degradação ambiental, a partir de condutas pedagógicas que negligenciam a possibilidade da tomada de consciência coletiva em pequenos grupos, que, quando unidas em um mesmo propósito, são capazes de alterar o rumo dos acontecimentos e transformar a realidade (FREIRE, 1967). Assim, é urgente que essa visão fatalista seja substituída pela formação de indivíduos livres, com posturas críticas, capazes de vislumbrar os problemas, construir perguntas, arquitetar hipóteses e propor soluções, intervindo de forma consciente em sua realidade.

Pensando nesses problemas, a presente pesquisa propõe uma prática pedagógica pau-tada no letramento científico, haja vista seu caráter investigativo diante de situações-problema da vida real, instigando o aluno/ pesquisador a refletir sobre possíveis soluções para os desafios ambientais de seu cotidiano, com base no conhecimento fornecido pela ciência e com o auxílio da tecnologia para o acesso e sistematização de informações.

A presença da tecnologia neste contexto se justifica porque sua disseminação no cotidiano dos indivíduos exige reflexões da escola sobre suas possíveis contribuições para a dinâmica das práticas docentes. Exigenos, portanto, repensar constantemente o contexto da edu-cação formal, que precisa estar em sintonia com essas novas formas de circulação das infor-mações. Sobre as ferramentas digitais na escola, Tezani (2011) aponta que elas 
abrangem desde ações de comunicação, agilidades, busca de informações, até a autonomia individual, ampliando suas possibilidades de in-serções na sociedade da informação e do conhecimento (Tezani, 2011, p.36).

Portanto, tendo em vista sua contribuição positiva para a educação formal, buscamos aliar este recurso a uma proposta de prática pedagógica pautada no letramento científico na escola. No contexto deste artigo, entenderemos por letramento científico a formação cidadã de aprendentes dos anos iniciais do Ensino Fundamental para dominarem com consciência a utilização dos conhecimentos científicos, bem como seus possíveis desdobramentos em diferentes esferas de sua realidade local (SASSERON; CARVALHO, 2011). Almejamos que este indivíduo seja capaz de relacionar o conhecimento científico e tecnológico aprendido na escola ao seu cotidiano, fazendo relações entre ele e o seu contexto sócio-histórico. (MAMEDE; ZIMMERMANN, 2005). Diante disso, optamos pela utilização do termo letramento em detrimento do termo alfabetização, devido às práticas efetivas de leitura e escrita no plano social a que ele remete.

Vale ressaltar, porém, que o nosso objetivo ao se utilizar do letramento científico como uma base teórica para práticas pedagógicas no ensino fundamental não é o de formar cientistas, mas, sim, o de levar os alunos a compreenderem como estes estudiosos veem, falam e explicam os fenômenos naturais. Dessa forma, estaríamos promovendo o acesso a esta forma de produzir conhecimentos, bem como o entendimento do mundo sob um especial ponto de vista - o científico (MOTOKANE, 2015).

Sobre esta temática, Lorenzetti e Delizoicov dissertam que as aulas pautadas no letra-mento científico, que são desenvolvidas em espaços não formais, como museus e centros de ciências, planetários, museus de história natural, zoológicos, jardins botânicos, parques nacio-nais e outros (2001, p. 2), podem ampliar as possibilidades de aprendizagem dos estudantes, pois despertam suas emoções e, consequentemente, sua motivação para a aprendizagem, além de terem um impacto positivo na memória a longo prazo.

Nesse sentido, o caráter lúdico destes espaços de aprendizagem também o configuram como um importante elemento para a alfabetização científica de crianças pequenas (ZIMMER-MANN e MAMEDE, 2005) e, ainda, contribuem significativamente para o trabalho pedagógico relacionado à Educação Ambiental (EA).

Perante o exposto, vale destacar que as práticas educativas relacionadas à EA no Brasil seguem as orientações da Política Nacional de Educação Ambiental, da qual podemos desta-car o Art. 1. ${ }^{\circ}:$

Entende-se por educação ambiental os processos por meio dos quais o indivíduo e a coletividade constroem valores sociais, conhecimentos, habilidades, atitud es e competências voltadas para a conservação do meio ambiente, bem de uso comum do povo, essencial à sadia qualidade de vida e sua sustentabilidade (LEI 9.795, 1999, art. $1^{\circ}$ apud DIAS, 2015, p. 5) Ao analisar os demais artigos desta política educacional, notamos que seu principal objetivo é, justamente, orientar possíveis práticas educacionais para que levem o aluno a compreender a concepção do meio ambiente em sua totalidade, considerando a interdependência entre o meio natural, o socioeconômico e o cultural, através de um enfoque humanista, holístico, democrático e participativo, incentivando a participação individual e coletiva dele na preservação do equilíbrio do meio ambiente, entendendo esta prática como um valor inseparável ao exercício da cidadania (LEI 9.795, 1999 apud DIAS, 2015, p. 5). Propõe, ainda, uma prática educativa integrada às diferentes áreas do conhecimento, excluindo a possibilidade de uma disciplina específica para o ensino de EA.

Nesse contexto, verifica-se que a Educação Ambiental pode tornar-se potencialmente significativa quando abordada em espaços de educação não formais, como exemplificados anteriormente, e que pode ser trabalhada a partir de atividades investigativas, pautadas no letramento científico.

Diante disso, constatamos que a abordagem destes conteúdos na escola não deveria ser realizada de forma descontextualizada à realidade dos alunos, por meio da memorização de conceitos e definições presentes em livros didáticos, mas necessitariam de conexões com reais situações-problema. Tais atividades estariam subordinadas a um objetivo geral de cunho norteador, que poderia instigar a busca por respostas e a construção de conhecimentos científicos sobre EA pelos alunos, possibilitando, assim, uma formação autônoma e crítica.

Com base no exposto, propomos um trabalho pautado no letramento científico que trabalhe conceitos relacionados à Educação Ambiental através de atividades sequenciais e progressivas, guiadas ou por um tema ou por um objetivo geral (MACHADO; CRISTOVÃO, 2006), o qual denominamos Sequência Didática (SD). 
Entendemos que este termo se remete ao planejamento de aula contínuo de forma gradual, que parte dos níveis de conhecimentos já dominados pelos alunos para chegar àqueles que eles precisam compreender (Id; 2010) e acreditamos que as ferramentas digitais podem ser um recurso auxiliador nesse processo. Assim, a SD proposta neste artigo tem seu ponto de partida nos conhecimentos prévios dos alunos referentes à EA e busca ampliá-los gradativamente, através de pesquisas de campo, explorações de informações através de recursos tecnológicos, sistematização de hipóteses e conclusões pelos alunos.

Segundo Machado e Cristovão (2006, p. 8), as Sequências Didáticas têm uma aborda-gem que implicam uma lógica de descompartimentalização dos conteúdos, o que favorece a prática pedagógica interdisciplinar no planejamento do docente. Os autores afirmam ainda que este procedimento didático é justificado pelo trabalho global e integrado do qual favorece; pela integração das atividades de acordo com uma ordem sequencial flexível pré-elaborada; e pela motivação instigada aos alunos, uma vez que o permite vislumbrar diferentes objetivos específicos dentro de um objetivo geral norteador.

Nesse sentido, é fundamental explicitar, ainda, o papel do professor neste processo, ressaltando a importância de que ele domine o assunto pesquisado em toda sua complexidade, de modo que possíveis apropriações de discursos alheios pelos alunos sejam evitados, bem como a construção de ideias equivocadas. Uma vez internalizadas, difícil será o processo de sua desconstrução. (MOTOKANE, 2015).

\section{Metodologia}

Durante as etapas de planejamento desta atividade de uma proposta de prática pedagógica, visitamos o Centro Histórico Sítio Roberto Burle Marx (Figura 1), situado na Barra de Guaratiba, em local bem próximo às instituições de ensino do bairro. O intuito de tal experiência foi, justamente, conhecer o potencial exploratório e investigativo do referido espaço não formal de aprendizagem em possíveis atividades pedagógicas para o letramento científico realizadas com alunos do entorno do SRBM, bem como conhecer o acervo botânico que ele oferece para tais explorações.

Após a visita guiada, foram realizadas discussões entre os três autores deste artigo acerca dos temas e conteúdos pertinentes a serem elencados na prática pedagógica. Os atores deste trabalho discutiram e refletiram também sobre a relevância dessa seleção curricular para os habitantes da região, sobre a necessidade de estímulos prévios, realizados ainda no território das escolas, para despertar a curiosidade dos alunos para exploração do território do Sítio. Finalmente, refletimos sobre estratégias lúdicas para que esta motivação inicial fosse despertada e para que ela pudesse culminar em investigações mais aprofundadas pelos alu-nos, envolvendo reflexões de caráter socioambiental relacionadas com o bairro de Guaratiba.

Em um outro momento os autores fizeram um levantamento das possibilidades de uso de algumas ferramentas tecnológicas como o software PlantNET e o Google Hearth PRO para ser incorporada a uma estratégia didática para o letramento científico.

Fundamentados por essas questões, observações e análises, foi elaborada uma proposta de Sequência Didática, apresentada no capítulo cinco deste artigo, com uso de tecnologias híbridas, para que seja utilizada futuramente em atividades com uma proposta pedagógica fundamentada para o letramento científico.

\section{A Visita Guiada ao Sítio Roberto Burle Marx}

Durante a visita guiada, os autores vivenciaram diferentes situações de descoberta en-volvendo a construção de saberes científicos, relacionando-os a diversificados temas como, por exemplo, botânica, reflorestamento e educação ambiental. Descobrimos que o local recebe diariamente turistas, pesquisadores e estudantes de todo o Brasil e que possui enorme potencial para o desenvolvimento de práticas educativas que visam à formação de alunos letrados cientificamente. Além disso, percebemos que o SRBM concentra coleções de arte sacra, pinturas e esculturas do próprio Burle Marx e de artistas contemporâneos, arte pré-colombiana, obras de arte 
popular brasileira em cerâmica (principalmente do Vale do Jequitinhonha) e madeira, mobiliário e objetos de decoração, bem como uma coleção de conchas (IPHAN, 2012). Tais artefatos artísticos e históricos são riquíssimos para serem explorados em ocasiões futuras, em aulas pautadas em investigações históricas, a partir da exploração deste acervo artístico local.

Com base nessas experiências, discutimos, ao final da visita ao Sítio e ainda imersos em seu ambiente, sobre possíveis estratégias pedagógicas significativas para alunos dos anos iniciais do ensino fundamental dentro deste local e nos questionamos sobre a necessidade de utilização de tecnologias durante a visitação, que pudessem auxiliar o aluno/pesquisador na identificação das espécies vegetais ali presentes. Discutimos também sobre a relevância do uso de tecnologias como fontes de informação para a descoberta dos locais de origem delas.

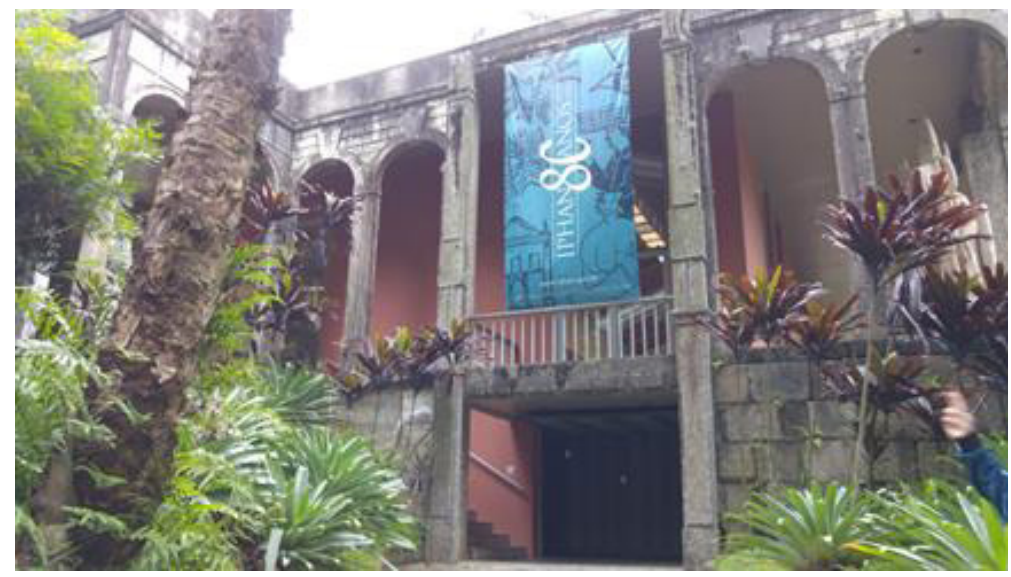

Figura 1: Registro fotográfico realizado durante a visitação dos autores deste artigo ao Sítio Roberto Burle Marx. Fonte: Monalisa Silva.

\section{Uma proposta de sequência didática interdisciplinar utilizando tecnolo- gias híbridas para promover a educação mbiental}

A Sequência Didática proposta tem como pano de fundo o cenário ambiental na contemporaneidade. Sobre este cenário, é importante citar que a preservação da Mata Atlântica foi indicada como uma das prioridades dos órgãos públicos para a conservação da biodiversidade da Terra, entretanto, ainda sim, ela vem sendo destruída pela ação antrópica (ALMEIDA, 2016).

Nesse contexto, torna-se válido considerar que a cidade do Rio de Janeiro está inteira-mente inserida neste bioma, e que o bairro de Barra de Guaratiba possui esta característica ainda mais evidente. Caracterizado por abrigar a Mata Atlântica, o Manguezal e o ecossistema de Restinga, este bairro concentra uma riquíssima biodiversidade, encontrada tanto na Reserva Biológica Estadual de Guaratiba, quanto nas duas unidades de conservação ambiental - PNM da Prainha e PNM de Grumari - que formam parte do Parque Estadual da Pedra Branca. Em vista disso, tem-se a importância de sua valorização pelos residentes locais, bem como a constante demanda por estratégias para sua preservação.

Sendo as autoras deste artigo moradoras dessa região desde o nascimento e levando em consideração suas experiências de contato com estes ecossistemas, muitas vezes sendo vistos poluídos ou explorados de forma insustentável, consideramos relevante, a partir da revisão de literatura realizada, desenvolver uma prática educativa que auxilie o aluno inserido no contexto de Barra de Guaratiba a pensar cientificamente, tecendo articulações entre o conhecimento científico e a realidade em que está inserido, para que este seja capaz de pensar em estratégias de conservação e de proteção de seu bairro. 
Priorizamos, para isso, contribuir para a formação de um indivíduo dentro da perspectiva do letramento científico já que este lhe dá subsídios para adotar um caráter investigativo diante de situações-problema como a supracitada no parágrafo anterior, instigando-o a refletir sobre possíveis soluções para os desafios ambientais de seu cotidiano, com base no conhecimento fornecido pela ciência e com o auxílio da tecnologia para o acesso e sistematização de informações (MAMEDE; ZIMMERMANN, 2005).

A prática educativa elaborada pelos autores deste artigo tem como propósito, portanto, contribuir para a formação de alunos letrados cientificamente. Em um futuro próximo, pretende-se aplicá-la com alunos do referido bairro, para avaliar suas contribuições à finalidade supracitada.

Portanto, diante dessas reflexões sobre as potencialidades pedagógicas que este espaço não formal dispõe, bem como de tecnologias que poderiam auxiliar em práticas educativas ali realizadas, elaboramos a proposta de uma Sequência Didática interdisciplinar, disposta no Quadro 1. Além dessas reflexões, sua elaboração também levou em consideração os princí-pios norteadores da fundamentação teórica.

A proposta para ser usada, em futuras pratica pedagógicas, inicia-se com o levantamen-to de hipóteses provenientes da leitura de um conto infantil intitulado A Viagem da Sementinha (SIGUEMOTO; MARTINEZ, 2012). É Importante destacar que esta proposta se funda-menta no princípio da flexibilidade de caminhos e trajetórias investigativas que podem ser percorridas pelos alunos, na valorização do protagonismo discente, na ludicidade e na curiosidade presente no cotidiano infantil. Como já supracitado, seu principal objetivo é contribuir para formação de alunos capazes de tecer articulações entre o conhecimento científico e sua realidade local (MAMEDE; ZIMMERMANN, 2005), mais especificamente, a realidade do bairro de Barra de Guaratiba.

Após a leitura do livro, a atividade se desdobrará em uma tempestade de ideias a ser realizada coletivamente entre o professor mediador da atividade e os alunos participantes. Com base nos questionamentos e nas hipóteses levantadas a partir do texto, ela propõe uma pes-quisa de campo dentro do Sítio Roberto Burle Marx, utilizando o aplicativo tecnológico PlantNet (detalhado na subseção 6.1) para exploração das origens de espécies vegetais do local. Por fim, sugere a sistematização dos dados coletados na pesquisa de campo com o auxílio do software Google Earth Pro (detalhado na subseção 6.2) e a retomada das hipóteses iniciais para discussão e construção de novos problemas por meio de um debate em sala de aula (espaço formal).

\section{Leitura coletiva do Livro A Viagem da Sementinha (SIGUEMOTO; MARTINEZ, 2012).}

O livro narra a viagem de uma sementinha aventureira que é levada pelo vento e conhece diferentes ecossistemas, até cair em um viaduto e se transformar em uma grande árvore. Na narrativa, a disseminação da semente ocorreu pela ação da própria natureza, a partir do vento.

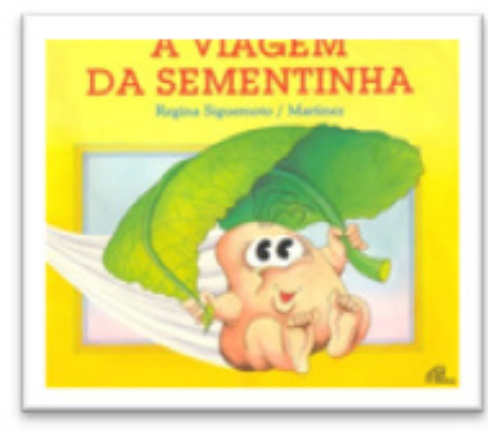

Figura 2: Capa do Livro A Viagem da Sementinha (SIGUEMOTO, 2012). Fonte: SIGUEMOTO, R. A Viagem da Sementinha. São Paulo: Paulinas, 2012. 
A partir da história...

Questionamentos iniciais sobre a disseminação de sementes na natureza e levantamento de hipóteses:

- Como vocês acham que ocorre a disseminação de sementes na natureza?

- Quem são os agentes responsáveis por essa disseminação? Será que o homem também pode ser um propagador de sementes?

- Quais espécies vegetais existem ao nosso redor? Vocês sabem de onde elas vieram?

- Quem as trouxe até aqui e o quanto elas viajaram para chegar onde estão?

Desenhos, esquemas e registros orais das hipóteses iniciais dos alunos e, com base nesse material, construção de equipes de investigação que possuam compatibilidade de hipóteses.

Com o objetivo de responder a esses questionamentos, propor uma pesquisa de campo ao local do bairro considerado referência em diversidade biológica, para explorar suas espécies vegetais.

\section{Pesquisa de campo no Sítio Roberto Burle Marx com a utilização do aplicativo identifi- cador de plantas PlantNet, para explorar as espécies vegetais do local e descobrir suas origens:}

PlantNet: É um aplicativo de reconhecimento tanto de folhas quanto de flores, frutos e caules, e permite identificar milhares de espécies da flora silvestre e metropolitana (RIBEIRO, 2015). É possível encontrar mais detalhes sobre o seu funcionamento mais adiante neste artigo.

A experiência objetiva favorecer inúmeras descobertas, relacionadas com:

- A origem das sementes do sítio;

- $\quad$ Agentes disseminadores das sementes do Sítio (a propagação de sementes foi realizada pela ação do homem);

- Transformações ocorridas no território do local após as sementes chegarem de viagem, uma vez que no passado era uma área degradada pela ação antrópica;

- O conceito de reflorestamento e quais são os seus pilares. O SRBM é um claro exemplo de um ambiente reflorestado, algo facilmente perceptível a partir da observação de sua biodiversidade, da geografia do seu terreno, da organização e do planejamento do seu território, entre outros fatores.

\section{Sistematização dos dados coletados com o auxílio do Software Google Earth Pro:}

Google Earth Pro: Em sua versão para desktop, é possível descobrir de onde veio cada planta observada no Sítio e o quanto ela viajou para chegar até ele, a partir do uso do recurso de medição de distâncias entre diferentes pontos da Terra. Mais detalhes sobre o funcionamento desse software mais adiante neste artigo. 
Durante a utilização desse software, realizar a sistematização das origens das plantas encontradas através de uma busca desses locais em seu globo terrestre virtual.

Construção coletiva de uma tabela de sistematização da distância viajada por cada planta coletada.

\section{Retomada das hipóteses iniciais e abertura para a construção de novos problemas:}

Comparação das hipóteses iniciais com os conhecimentos construídos até o momento.

A partir das conclusões, promover um debate entre as equipes, envolvendo questões de caráter socioambiental, como:

- Como era a área do sítio antes da chegada das sementes trazidas por Roberto Burle Marx e como ela está agora?

- Qualquer pessoa poderia construir este tipo de ambiente reflorestado?

- Tendo em vista a complexidade que envolve essa construção e a quantidade de recursos que se exige, que postura nós deveríamos adotar diante de ecossistemas nativos?

- Como a comunidade escolar poderia ajudar na preservação dos biomas naturais do nosso bairro, uma vez que reflorestá-los seria algo significativamente mais complexo?

A partir dessas questões, é possível que surjam novos problemas e trajetórias investigativas, delineadas pelos próprios alunos.

Quadro 1: Sistematização da proposta de Sequência Didática Interdisciplinar.

\section{Esquema dos conteúdos envolvidos na sequência didática}

A partir da supracitada proposta de SD, elencamos abaixo um esquema de alguns dos conteúdos curriculares envolvidos em suas etapas investigativas. Por meio desta aclaração visual, se torna possível perceber o caráter interdisciplinar desta Sequência, uma vez que, nela, os conteúdos se articulam a partir de uma visão global do assunto investigado, ou seja, con-siderando todas as esferas de conhecimento presentes em sua temática.

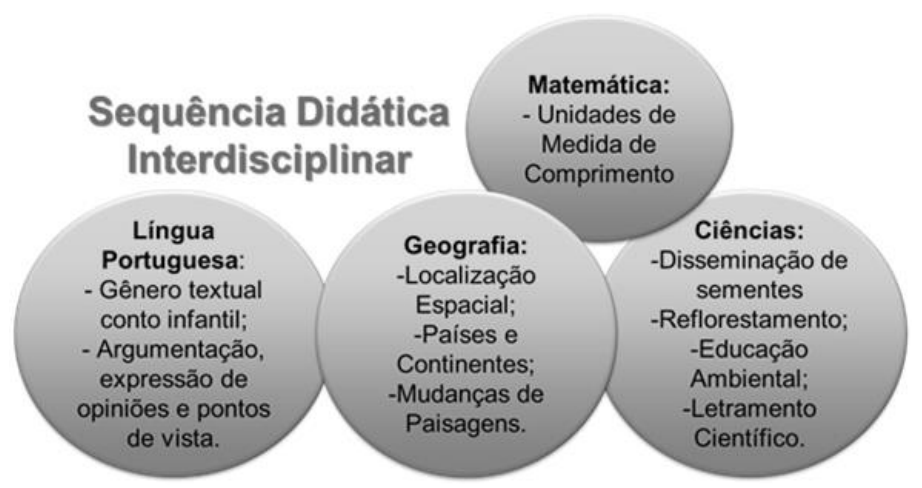

Figura 3: Esquema de sistematização dos conteúdos da Sequência Didática. 


\section{Apreciação das tecnologias Plantnet e Google Earth Pro apreciação das tecnologias}

\section{O aplicativo PlantNet:}

O PlantNet é um aplicativo gratuito para dispositivos Android e iOS, que foi desenvolvi-do por cinco organizações francesas - French Agricultural Research Centre for International Development (CIRAD), French National Institute for Agricultural Research (INRA), Institut National de Recherche en Informatique et en Automatique (INRIA), Institut de Recherche pour le Développement (IRD) e Tela Botanica - em um projeto financiado por Agropolis Fondation. Permite identificar plantas através de fotografias, realizadas a partir de dispositivos mobile. Com relação aos seus prerrequisitos, é necessário que o aparelho seja equipado com câmera digital e GPS. Ao fotografar uma espécie vegetal, o aplicativo realiza um escaneamento e faz associação entre as características da planta fotografada com outras de seu banco de dados. Ao final, ele oferece alguns resultados encontrados e o usuário escolhe qual deles seria a planta buscada. O PlantNet se propõe a ser um aplicativo de reconhecimento tanto de folhas quanto de flores, frutos e caules, permitindo identificar milhares de espécies da flora silvestre e metropolitana. Funciona integrado com a câmera e o GPS do dispositivo móvel, apresentando vários comandos para melhorar a bases de dados das plantas já cadastradas. Também permite pesquisar informações mais complexas e compartilhá-las em contas de Facebook e Twitter, além de possibilitar a visualização de redes de fotos compartilhadas, criação de banco de dados com imagens e a criação de um perfil para interagir com outros colaboradores (RIBEIRO, 2015).

Acredita-se que a utilização do PlantNet nas escolas e, mais especificamente, nesta SD poderia favorecer o acesso rápido a um grande número de informações relevantes para a investigação proposta, possibilitando aos alunos experiências em que precisam dominar e utilizar, com consciência, os conhecimentos científicos relacionados com a botânica, bem como realizar articulações entre esses conhecimentos com a sua realidade local. O fato de o aplicativo posicionar o usuário como colaborador de informações traz ao aluno a responsabilidade de atuar como pesquisador e avaliador das informações com as quais está em contato, tomando decisões, acrescentando dados e compartilhando-os com uma rede de pessoas que fazem parte do mesmo universo investigativo. Assim, acreditamos que a utilização deste aplicativo no contexto desta Sequência Didática tem grande potencial para favorecer o desenvolvimento de alunos letrados cientificamente, uma vez que, de acordo com Mamede e Zimmermann (2005, p.2), estes são capazes de fazer uso do conhecimento científico e tecnológico no cotidiano, no interior de um contexto sócio-histórico específico, acessando com consciência informações científicas, contribuindo em bancos de dados mundiais e interagindo com outros pesquisadores.

Em razão das considerações feitas, avaliamos que o aplicativo se mostra útil para a in-vestigação proposta, porém possui alguns aspectos deficientes. Sua base de dados, por exemplo, ainda é insuficiente e, por isso, não consegue identificar todas as plantas do Sítio Roberto Burle Marx de forma eficaz. Nesse sentido, outros aplicativos como Garden Answers Plant Identifier apresentam melhores resultados. Ademais, o PlantNet demanda uma grande quantidade de cliques do usuário para se chegar até a informação desejada, prejudicando a objetividade e a localização das informações de forma rápida. $\mathrm{O}$ aplicativo necessita de internet e, portanto, só é possível identificar espécies vegetais no Sítio Roberto Burle Marx através da rede de dados móveis disponível no dispositivo do próprio usuário, dada a inexistência de rede WiFi no local. 


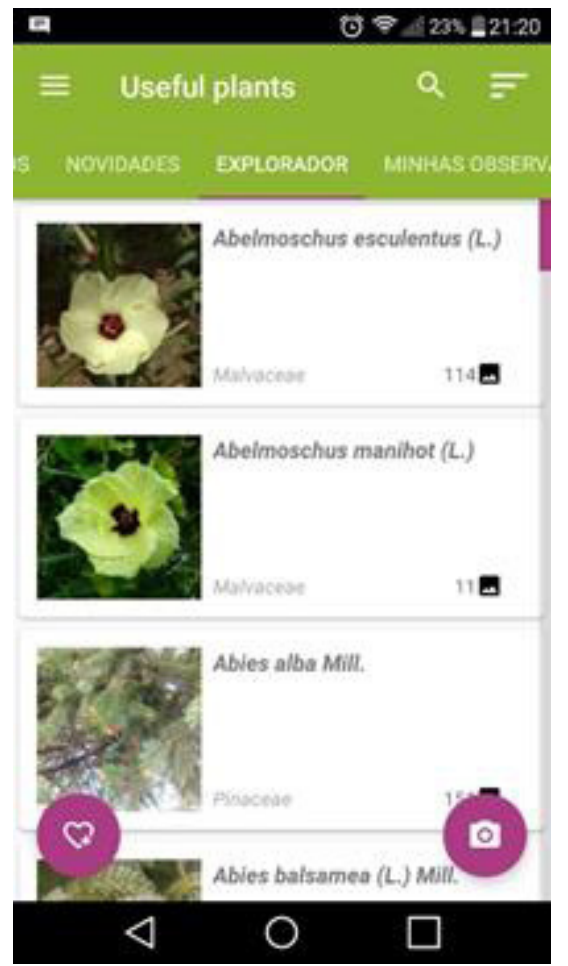

Figura 4: Captura de tela da interface inicial do Aplicativo PlantNet.

\section{O software Google Earth Pro}

Desenvolvido pela Google Inc., o Google Earth Pro pode ser considerado uma geotec-nologia que permite uma visão em três dimensões do globo terrestre, possibilitando uma exploração virtual do planeta Terra (SILVA; CARNEIRO, 2012). Está disponível gratuitamente para diversos sistemas operacionais e traz integração com o Street View e o Google Maps, podendo ser utilizado tanto online quanto offline. Dentre os inúmeros recursos que oferece, o mais relevante para esta proposta seria a medição precisa de distâncias entre dois pontos do globo, a partir de diferentes unidades de medida. Além deste, a possibilidade de impressão de imagens e de exploração mais aprofundada dos locais mais remotos do planeta também são mecanis-mos disponíveis que se mostram interessantes e de grande potencial de uso nesta situação investigativa.

Acredita-se que este software no contexto escolar e, mais especificamente, nesta SD poderia oferecer ao aluno uma poderosa ferramenta com informações sobre os espaços geo-gráficos percorridos pelas sementes, além de potencializar vivências de exploração, orientação e localização de diferentes regiões do planeta, algo que pode ser útil nesta e nas mais diversas pesquisas exploratórias e investigações científicas. Isso porque o Google Earth Pro permite ao aluno acesso fácil e rápido a informações relevantes para descobrir a distância percorrida pelas diferentes espécies vegetais investigadas, auxiliando os alunos a vivenciarem situações que lhes exige dominar e a utilizar com consciência a tecnologia em favor da construção de conhecimentos científicos, bem como realizar articulações entre esses conhecimentos com a sua realidade local.

Nesse sentido, Mamede e Zimmermann (2005) versam que o ensino pautado no letra-mento científico não é centrado unicamente no conteúdo em si, mas nas suas relações com a vida do indivíduo em seu cotidiano e da sociedade de uma maneira mais ampla (p. 2). Acredi-tamos, portanto, que esta ferramenta digital propicia uma visão dos alunos sobre o planeta de forma ampla, favorecendo o seu entendimento sobre a origem das sementes encontradas no Sítio e o local de onde vieram. Além disso, acreditamos que, assim como 
o PlantNet, a utiliza-ção deste software no contexto desta Sequência Didática tem grande potencial para favorecer o desenvolvimento de alunos letrados cientificamente, que sabem filtrar e acessar informações científicas, tecendo relações com seu contexto sócio-histórico.

No entanto, apontamos como uma limitação desse software a ausência do recurso de medição de distâncias na sua versão mobile, algo que demanda uma maior infraestrutura da escola, já que é necessário disponibilizar computadores para as equipes fazerem uso da ver-são para desktop do software, quando, na verdade, seria mais fácil acessar essas informações pelo próprio dispositivo móvel, sem sair da sala de aula ou do ambiente em que se realiza a pesquisa. Entretanto, ainda sim, a partir da supracitada análise de suas potencialidades, concluímos que o Google Earth Pro se mostra uma ferramenta relevante para a promoção do letramento científico no contexto da Sequência Didática elaborada.

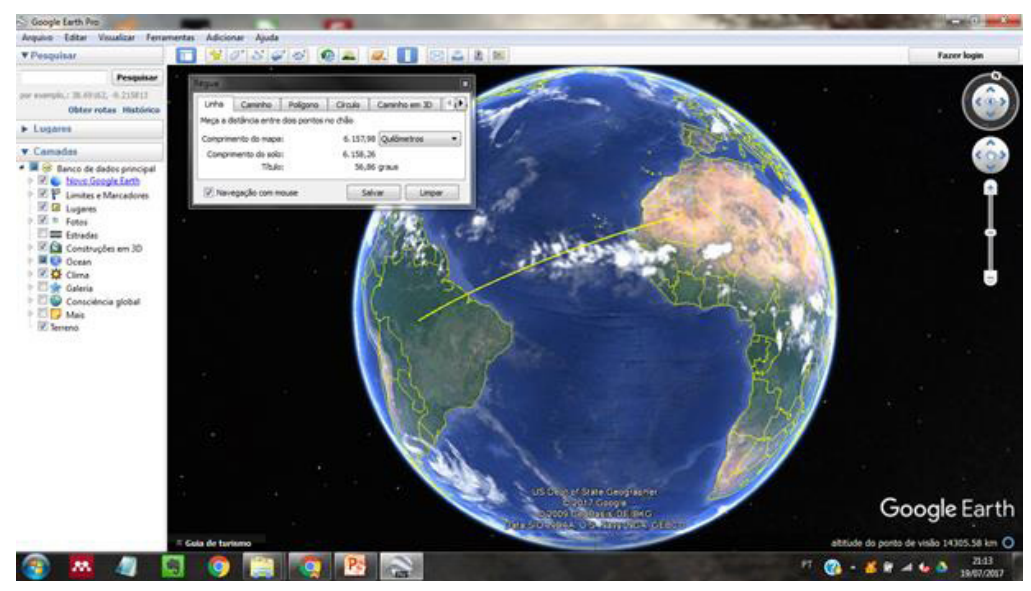

Figura 5: Captura de tela da função de medição de distâncias do software Google Earth Pro.

\section{Considerações finais}

$\mathrm{Na}$ visita ao referido espaço não formal de aprendizagem, o Sítio Burle Max, os autores vivenciaram uma experiência enriquecedora para despertar o olhar, enquanto educadores, ao potencial pedagógico que ambientes como este oferecem e que nem sempre são explorados em atividades escolares, mesmo estando bem próximos à instituição. Assim sendo, quando as instituições de ensino ampliam suas atividades em outros locais, como aqueles abertos às experimentações reais, a curiosidade, a exploração e investigação autônoma dos alunos podem ser instigadas pelo professor, visando a construção coletiva de saberes.

Entretanto, a realização dessas atividades educativas depende de um olhar atento e sensível da equipe escolar para buscar museus, parques, exposições, sítios, entre outros, conhecê-los e investigá-los, analisando o potencial que possuem para aprendizagens significativas. Nesse sentido, implementar situações de investigação fora dos muros da escola demanda professores que, habitualmente, visitam e exploram locais ao seu redor, ou seja, que se interessam por esses espaços e que reconhecem suas contribuições às práticas escolares.

A visita ao Sítio Burle Marx possibilitou experienciar sensações, manusear tecnologias, conhecer previamente o ambiente a ser explorado pelos alunos e pensar sobre estratégias que oportunizem práticas significativas. Com base nisso, percebeu-se que esses espaços, quando conhecidos previamente pelo professor, podem ser utilizados de forma mais proveitosa, transcendendo uma simples proposta de visita guiada no local e possibilitando investigações mais autônomas pelos alunos.

Sobre a SD elaborada, é possível perceber que o desenvolvimento da proposta está pautado na utilização de tecnologias digitais dentro e fora do referido espaço não formal de aprendizagem, bem como em uma abordagem de caráter investigativo pelos alunos para o uso desses recursos, algo que estimula a busca e 
sistematização de informações. Ela busca favorecer a valorização do protagonismo infantil e do pensamento científico, transcendendo os muros das escolas localizadas na região da Barra de Guaratiba em direção a uma educação que desperte a importância dos ecossistemas presentes no bairro. Acredita-se que somente essa qualidade (entre muitas outras) já será uma razão para introduzir esta Sequência Didática em uma prática educativa relevante para a formação de alunos/pesquisadores com senso crítico, capazes de vislumbrar problemas, construir perguntas, arquitetar hipóteses e propor soluções, intervindo de forma consciente em sua realidade.

É possível perceber, ainda, que tal prática tem potencial para auxiliar de forma eficaz em experiências significativas de construção do pensamento científico e na ampliação do repertório de conhecimentos dos alunos da região, entre outros aspectos, todos fundamentais na formação de um indivíduo capaz de relacionar o conhecimento científico e tecnológico aprendido com o seu dia a dia, compreendendo como os estudiosos veem, falam e explicam os fenômenos naturais.

Vale ainda ressaltar que observamos em cada tecnologia selecionada para esta SD uma infinidade de informações, mas que utilização dos recursos como favorecedores do desenvolvimento do letramento científico só será possível se tais recursos estiverem pautados em uma utilização crítica, consciente e proficiente, capazes de motivar uma mudança de postura dos alunos em relação à ciência (MAMEDE; ZIMMERMANN, 2005). Neste sentido, durante a Se-quência Didática, o aluno necessitará de orientações do professor sobre estratégias de locali-zação das informações pertinentes de forma objetiva, desenvolvendo um olhar crítico e seletivo diante dos conteúdos com os quais se depara. Este educador, portanto, deve estar atento tanto para as potencialidades que elas oferecem quanto para as limitações e desvantagens que envolvem seu uso na escola, tendo claro seu papel de mediador durante as atividades, no sentido direcioná-las à produção de argumentos válidos pelos alunos, baseados em conhecimentos científicos (MOTOKANE, 2015).

A análise realizada sobre o aplicativo PlantNet mostrou que, apesar de ser o mais ade-quado para esta pesquisa de campo, em comparação com outros similares disponíveis, como o Smart'Flore , Herbarium, GreenSnap , Flore de Poche e o Que Flor é esta?, ele ainda possui inúmeras limitações, o que nos levou a avaliar a necessidade de criação de um aplicativo sobre o Sítio Roberto Burle Marx, com detalhes de sua história e as informações específicas sobre as espécies vegetais que ele abriga. Torna-se relevante para o futuro uma investigação sobre a aplicação deste recurso, no sentido de avaliar se ele teria potencial, tanto para enriquecer ainda mais a experiência do aluno/pesquisador durante a visita ao Sítio, quanto para contribuir de forma positiva nas aulas de EA para o desenvolvimento do letramento científico dos alunos.

Assim, uma proposta de SD com abordagem interdisciplinar baseada nos conceitos supracitados, que trabalhe a Educação Ambiental, pode ser considerada, neste procedimento didático, não só o fator motivacional favorecido pelos recursos digitais, mas também seu potencial educativo para busca e sistematização de informações, em detrimento da leitura superficial comumente realizada na web. Busca-se, desta forma, possibilitar futuramente ao aluno uma utilização consciente e proficiente da tecnologia, extraindo deste recurso as informações pertinentes das quais necessita, em dada situação, para tecer um olhar crítico e seletivo diante delas.

A partir dessas características e princípios nas quais a referida SD está pautada, consideramos, portanto, que ela pode potencializar a ampliação de práticas sociais de leitura e escrita científica de alunos dos anos iniciais do ensino fundamental, potencializando a participação individual e coletiva dele na resolução de problemas contemporâneos. A possibilidade de se expressar, de deliberar estratégias e caminhos e de criar teorias e conclusões em que ela se sustenta propicia a valorização da pluralidade presente na escola e é um dos meios possíveis para ajudar os professores a desenvolver em sala de aula uma educação para a tomada de decisão e para a responsabilidade social e política (FREIRE, 1967), objetivos indispensáveis à educação escolar.

\section{Notas}

1. O Sítio Roberto Burle Marx (SRBM), foi construído em 1973, em um terreno antes profunda-mente degradado pela ação humana em Barra de Guaratiba. Seu idealizador foi o artista plás-tico e arquiteto-paisagista Roberto Burle Marx. O local foi sua residência por 21 anos e, durante esse tempo, viajou inúmeros locais do planeta, trazendo para ele novas plantas e obras de arte pelo mundo. Hoje, o Sítio abriga uma das mais importantes coleções de plantas vivas do planeta e é uma unidade 
especial do Instituto do Patrimônio Histórico e Artístico Nacional, órgão do Ministério da Cultura do Brasil (IPHAN, 2012). Mais informações disponíveis em: <http://portal.iphan.gov.br/pagina/detalhes/399/>.

2. Plant Net: Disponível para download em: <https://play.google.com/store/apps/details?id=org.plantnet\&hl=pt_BR $>$ ou $<$ https://itunes.apple.com/br/app/plantnet> Acesso em: 20 jul 2017.

3. Garden Answers Plant Identifier: Apesar de se apresentar como o melhor de sua categoria para identificação de espécies vegetais, sua utilização neste caso se torna inviável, já que possui a interface no idioma inglês, dificultando seu uso por crianças dos anos iniciais do ensino fundamental que ainda não dominam o idioma. (Garden Answers Plant Identifier está disponível para download em: https://play.google.com/store/apps/details?id=com.teamsoa.gardenanswers\&hl=pt_BR ou https://itunes.apple.com/br/app/garden-answers-plant-identification/id605855033?mt=8)

4. Google Earth Pro: Disponível para download em: <https://www.google.com.br/earth/download/gep/agree.html> Acesso em: 19 jul 2017.

5. Smart'Flore: Disponível para download através do endereço eletrônico: <https://play.google.com/store/apps/details?id=org. flore.smart.smartflore\&hl=fr>

6. Herbarium: Disponível apenas para dispositivos Android, através do endereço eletrônico: <https://play.google.com/store/apps/ details?id=org.altervista.paologianfelici.herbarium\&hl=pt_BR $>$.

7. GreenSnap: Disponível para download através do endereço eletrônico: <https://play.google.com/store/apps/details?id=jp. co.aainc.greensnap\&hl=pt_BR>.

8. Flore de Poche: Disponível para download através do endereço eletrônico: https://play.google.com/store/apps/details?id=fr. flore\&hl=pt_BR>.

9. Que Flor é esta?: Disponível para download através do endereço eletrônico: <https://play.google.com/store/apps/details?id=sk. ab.herbs\&hl=pt_BR>.

\section{Referências Bibliográficas}

ALMEIDA, D. S. Recuperação Ambiental da Mata Atlântica [online] 3 rd ed. rev. and enl. Ilhéus, BA: Editus, 2016. Disponível em: $<$ https://play.google.com/books/reader?id=l-cmDwAAQBAJ\&hl=pt-BR\&lr=\&printsec=frontcover\&pg=GBS.PA1>. Acesso: 01 ago. 2017.

COSTA, F. N. Estratégias de ensino-aprendizagem de ciências no Ensino Fundamental I para o início da alfabetização e letramento científico e atuação na ZDP. Tese de Doutorado. Uni-versidade de São Paulo - USP. São Paulo. 2016. Disponível em: http://www. teses.usp.br/teses/disponiveis/97/97138/tde-06022017-113329/en.php. Acesso: 31 jul. 2017.

DELIZOICOV, D.; LORENZETTI, L. Alfabetização científica no contexto das séries iniciais. Ensaio Pesquisa em educação em Ciências, v. 3, n. 1, p. 37-50, 2001. Disponível em: http://www.portal.fae.ufmg.br/seer/index.php/ensaio/article/view/35/66. Acesso: 20 jul. 2017.

DIAS, G. F. Atividades interdisciplinares de educação ambiental. Global Editora e Distribui-dora Ltda, 2015.

FREIRE, P. Educação Como Prática da Liberdade. Rio de Janeiro: Paz e Terra. 1967.

IPHAN. Sítio Roberto Burle Marx. Rio de Janeiro. 2012. Disponível em: <http://portal.iphan.gov.br/pagina/detalhes/399/>. Acesso: 20 jul. 2017.

MACHADO, A. R.; CRISTOVÃO, V. A construção de modelos didáticos de gêneros: aportes e questionamentos para o ensino de gêneros. Linguagem em (Dis) curso, v. 6, n. 3, p. 547-573, 2006. Disponível em: portaldeperiodicos.unisul.br/index.php/Linguagem_Discurso/article/view. Acesso: 19 jul. 2017.

MAMEDE, M.; ZIMMERMANN, E. Letramento científico e CTS na formação de professores para o ensino de ciências. Enseñanza de las Ciencias, n. Extra, p. 1-4, 2005. Disponível em: https://ddd.uab.cat/pub/edlc/edlc_a2005nEXTRA/edlc_a2005nEXTRAp320letcie.pdf. Acesso: 15 jul. 2017.

MOTOKANE, M. T. Sequências didáticas investigativas e argumentação no ensino de ecologia. Ensaio Pesquisa em Educação em Ciências (Belo Horizonte), v. 17, n. spe, p. 115-138, 2015. Disponível em: <http://www.scielo.br/scielo.php?pi$\mathrm{d}=$ S1983-21172015000400115> Aces-so: 20 jul. 2017.

RIBEIRO, D. PlantNet fotografa suas plantas para identificar a que espécies pertencem. 2015. Disponível em: http://www.techtudo. com.br/tudo-sobre/plantnet.html. Acesso: 19 jul. 2017.

SASSERON, L. H.; CARVALHO, A. Alfabetização científica: uma revisão bibliográfica. Investi-gações em ensino de ciências, v. 16, n. 1, p. 5977, 2011. Disponível em: https://www.if.ufrgs.br/cref/ojs/index.php/ienci/article/view/246/0. Acesso: 18 jul. 2017.

SIGUEMOTO, R. A Viagem da Sementinha. São Paulo: Paulinas, 2012.

SILVA, F. G.; CARNEIRO, C. R. Geotecnologias como recurso didático no ensino de geografia: experiência com o Google Earth. Caminhos de Geografia, v. 13, n. 41, 2012. Disponível em: http://www.seer.ufu.br/index.php/caminhosdegeografia/article/ view/16679. Acesso: 20 jul. 2017.

TEZANI, T. A educação escolar no contexto das tecnologias da informação e da comunicação: desafios e possibilidades para a prática pedagógica curricular. Bauru: Revistafaac. [online], p. 35-45. vol. 1, n. 1, set. 2011. Disponível em: http://www2.faac.unesp.br/ revistafaac/index.php/revista/article/view/11/5. Acesso em: 20 jul. 2017. 